\title{
14 School trauma-informed practice policy
}

\author{
Emily Berger and Karen Martin
}

\section{How to use this policy}

The purpose of this chapter is to provide an outline of a policy addressing trauma-informed practice in schools. This chapter will first define trauma and adverse childhood experiences and the implications of these experiences for children and adolescents. An outline of the trauma-informed practice policy for schools is then provided. This policy example is intentionally broad to enable and encourage school policy creators to adapt the example below to create a policy that best serves their school context.

[To adapt and use this policy, delete or modify the text as indicated]

\section{[INSERT name of school] Trauma-informed practice policy}

\section{Rationale}

Trauma and adverse childhood experiences include exposure to child physical abuse, sexual abuse, emotional abuse, physical neglect or emotional neglect, children having a parent with a mental illness or who abuses drugs or alcohol, having parents who become separated or divorced, or children who have a parent who has been incarcerated (Centers for Disease Control and Prevention [CDC], 2019). Trauma and adversity in childhood also include exposure to domestic violence in childhood, experiencing the death of a parent or significant other, exposure to refugee, terrorism, or war-related trauma, exposure to natural or manmade disasters, and experiencing an accident or injury (Perfect et al., 2016). Posttraumatic stress disorder (PTSD) may be diagnosed after a child or person experiences exposure to actual or threatened death, serious injury, or sexual violence (American Psychiatric Association [APA], 2013).

Children exposed to trauma are at higher risk of experiencing impaired executive functioning, delayed academic achievement, anti-social and disruptive classroom behaviour, school suspensions, and grade retention (Perfect et al., 2016). Trauma and adverse childhood experiences are also risk factors for psychological issues for children, including PTSD, depression, anxiety 
disorders, and conduct disorders (Perfect et al., 2016). Adverse childhood experiences also lead to greater engagement in health risk behaviours (e.g., alcohol abuse, drug use), physical morbidity, lowered academic achievement, higher unemployment, and welfare dependence in adulthood (CDC, 2019; Kezelman et al., 2015). More than two-thirds of children in the USA have been reported to experience at least one traumatic event before they are 16 years of age (Copeland et al., 2007).

\section{Purpose}

This school policy aims to address the issue of the impact of trauma and adverse childhood experiences on children in schools using a trauma-informed practice framework. It is recommended that all schools have a traumainformed practice policy. It is important to note that this policy does not address school mandatory reporting policy of child abuse and neglect. This policy should be used in conjunction with [INSERT name of school] policy on mandatory reporting of child abuse and neglect.

\section{Scope}

This policy applies to all school staff members, including teachers, school leaders, and school mental health workers for [INSERT name of school], and parents and students of [INSERT name of school]. The specific roles and responsibilities of school staff are listed according to the four Rs of traumainformed practice (see the following section) that were developed by the Substance Abuse and Mental Health Services Administration (SAMHSA, 2014), and the research evidence suggesting a whole-school education, support, and coaching program in response to childhood trauma (Berger, 2019; Dorado et al., 2016).

This policy does not include offending parents/carers, defined as the "parents who perpetrated the trauma for which the child is receiving treatment such as a parent who perpetrated the child's sexual abuse or domestic violence" (Cohen \& Mannarino, 2015, p. 557).

[INSERT specific roles and responsibilities of individuals or teams]

\section{Policy statement}

[INSERT name of school] will use the Substance Abuse and Mental Health Services Administration (SAMHSA) four Rs or a similar model to guide delivery of trauma-informed professional learning to school staff members. The four Rs include:

- Realisation of the impact of trauma and the potential pathways to recovery

- Recognition of the signs and symptoms of trauma in students 
- Responding to students impacted by trauma by incorporating knowledge about trauma and trauma-informed practice into classrooms and within [INSERT name of school]

- Resisting Re-traumatisation of students and secondary (vicarious) trauma of school staff through use of trauma-informed school policies, procedures, and practices (SAMHSA, 2014).

Realisation: [INSERT name of school] will ensure that all school staff members have access to professional learning about events and experiences that are considered traumatic and the potential effects of trauma and adverse childhood experiences on students (SAMHSA, 2014).

Recognition: [INSERT name of school] will ensure that all school staff have access to professional learning about the signs and symptoms that a student may have been exposed to trauma or adversity (SAMHSA, 2014).

Responding: [INSERT name of school] will ensure that all school staff have access to professional learning and ongoing coaching about incorporating knowledge of trauma and trauma-informed practice into classrooms and within [INSERT name of school] (SAMHSA, 2014).

Resisting Re-traumatisation: [INSERT name of school] will ensure that all students and school staff members are supported to avoid re-traumatising students who have experienced adversity or trauma, and to prevent secondary (vicarious) trauma of staff, through trauma-informed school policies, procedures, and practices (SAMHSA, 2014).

\section{Roles and responsibilities of school staff}

\section{All school staff roles and responsibilities}

All school staff are responsible for attending professional learning about trauma and how to implement trauma-informed practice in [INSERT name of school].

\section{School leaders' specific roles and responsibilities}

- School leaders at [INSERT name of school] will invest in trauma-informed practice, policy, and procedures within [INSERT name of school]. School leaders will invest through: ensuring that all school staff receive traumainformed professional learning; allocating appropriate facilities (e.g., therapy rooms, quiet spaces) for students exposed to trauma; employment of school staff who can provide trauma screening, assessment, and intervention services; and allocating school staff who can track and monitor the use of and recommend changes to the trauma-informed approach at [INSERT name of school].

- At [INSERT name of school] school leaders will: 
- Attend professional learning on the implementation of trauma-informed practice. This professional learning will encompass how to provide coaching and debriefing to school staff members, information on noticing the signs and symptoms of secondary (vicarious) traumatic stress among school staff, and detail how to support parents/carers of students exposed to trauma.

- Deliver a written school trauma-informed practice policy at [INSERT name of school] and ensure that all school staff members are familiar with this policy and the school mandatory reporting policy.

- Ensure that all school staff at [INSERT name of school] have received professional learning on childhood trauma and trauma-informed practice.

- Provide coaching and debriefing to school staff as they respond to students who have experienced trauma and when they use the principles of trauma-informed practice.

- Ensure that the physical environment of [INSERT name of school] is equipped to support the emotional regulation of students who have experienced trauma and the coaching and debriefing practices of school staff personnel.

- Refer students and parents/caregivers of students who have experienced trauma to mental health services and ensure that all parents/guardians are provided with information about the trauma-informed practice policies and procedures used at [INSERT name of school].

- Develop referral pathways to mental health providers and community services who can provide support to trauma-exposed students and their parents/guardians.

\section{School mental health workers' specific roles and responsibilities}

At [INSERT name of school] school mental health staff will:

- Attend professional learning on the implementation of trauma-informed practice. This professional learning will encompass how to provide coaching and debriefing to school staff team members, information on noticing the signs and symptoms of secondary (vicarious) traumatic stress among school staff, and detail how to support parents/carers of students exposed to trauma.

- Consult with school leadership on a written school trauma-informed practice policy at [INSERT name of school] and ensure that all school staff are familiar with this policy and the school mandatory reporting policy.

- Ensure that all school staff members at [INSERT name of school] have received professional learning on childhood trauma and trauma-informed practice.

- Provide coaching and debriefing to school staff as they respond to students who have experienced trauma and when they use the principles of trauma-informed practice.

- Ensure that the physical environment of [INSERT name of school] is equipped to support the emotional regulation of students who have experienced trauma and the coaching and debriefing practices of school staff. 
- Refer students and parents/caregivers of students who have experienced trauma to mental health services and ensure that all parents/guardians are provided with information about the trauma-informed practice policies and procedures used at [INSERT name of school].

- Attend professional learning about screening, assessment, and group and individualised treatment of trauma and traumatic stress disorders of children and adolescents.

- Provide screening, assessment, and group or individualised treatment to students who have experienced trauma. Including and supporting nonoffending parents/carers during therapy is also recommended where possible (Cohen \& Mannarino, 2015; Jaycox et al., 2009).

- Develop clear referral pathways to mental health providers and community services who can provide support to trauma-exposed students and parents/guardians.

- Liaise on a regular basis with the leadership team at [INSERT name of school], to ensure consistency in approach towards the student's wellbeing.

\section{School trauma-informed practice principles}

[INSERT name of school] will use an evidence-based trauma-informed framework (for example, the Attachment, Regulation, and Competency [ARC] framework) when responding to students who have been impacted by trauma (Blaustein \& Kinniburgh, 2018; Dorardo et al., 2016; Holmes et al., 2015). The ARC framework consists of the following school trauma-informed approaches, and this model is consistent with other evidence-based models for trauma-informed practice in schools (Berger, 2019).

Foundational Strategies: Foundational Strategies consists of enhanced student Engagement, Education, and Routines and Rhythms (Blaustein \& Kinniburgh, 2018).

Attachment: There are three pillars within the student-parent/caregiver Attachment domain - Caregiver Affect Management, Attunement, and Effective Response (Blaustein \& Kinniburgh, 2018).

Regulation: There are two target areas within the Regulation domain for students' emotional regulation - Identification and Modulation (of emotions; Blaustein \& Kinniburgh, 2018).

Competency: There are three target areas within the student enhanced Competency domain - Improved student: Executive Functions, Self-Development and Identity, and Relational Connection (Blaustein \& Kinniburgh, 2018).

Trauma-Experience Integration: Trauma-Experience Integration is the principle of increasing students' Distress Tolerance and Regulation, Curiosity and Reflection, and Engaging in Purposeful Action (Blaustein \& Kinniburgh, 2018).

[INSERT name of school] will deliver the Attachment, Regulation, and Competency (ARC) trauma-informed framework (or similar framework) across four tiers including: 
1 Professional learning for all school staff personnel about childhood trauma and trauma-informed practice

2 Ongoing group-based professional learning for school staff team members and group-based intervention for students who have been exposed to trauma

3 Ongoing individualised coaching for school staff members and individualised intervention for students who have been exposed to trauma

4 Engagement with external mental health providers and community services and education for parents/guardians about trauma-informed practice (Berger, 2019; Dorado et al., 2016).

\section{Rating of evidence base}

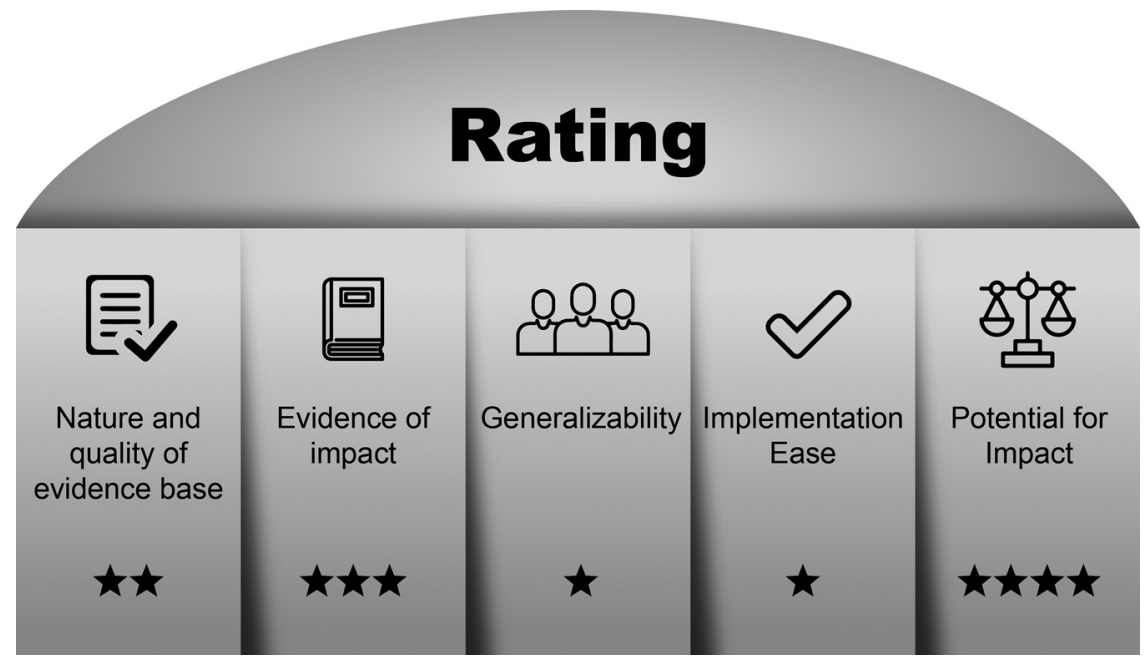

Figure 14.1. School Trauma-Informed Practice Rating of Evidence.

Author Note. This policy is based on growing evidence about the effectiveness of traumainformed practice for improved student wellbeing and teacher wellbeing. Research is of moderate quality but with some potential bias regarding the outcomes of traumainformed care. The research evidence used in the policy demonstrates moderate levels of impact but with limited evaluation of the outcomes of trauma-informed practice across time and settings. Minimal evidence has been provided on the effectiveness and sustainability of trauma-informed practice across different educational settings and student groups. Trauma-informed practice policy requires initial and ongoing training for all school staff, access to mental health professionals both within and external to the school, and changes in the school environment to facilitate student and staff wellbeing. School trauma-informed practice policy will address the initial and ongoing social, emotional, behavioural, and learning needs of the two-thirds of students impacted by trauma, as well as the needs of their parents/carers, and prevent re-traumatisation of children. It will also prevent secondary (vicarious) trauma and burnout among school staff members. 


\section{Authorship}

Dr Emily Berger, Monash University

Dr Karen Martin, The University of Western Australia

[INSERT RELEVANT STAFF MEMBERS]

\section{Related policies}

[INSERT RELEVANT POLICY AND DOCUMENTS]

Student wellbeing interventions

Personalised wellbeing planning

Supporting transitions

School belonging

Teacher wellbeing

Youth homelessness

Managing family violence

Mandatory reporting

\section{Date of ratification}

This policy was ratified on [INSERT DATE].

\section{Date of review}

This policy will be reviewed by [INSERT DATE].

\section{Further reading}

Blaustein, M. E., \& Kinniburgh, K. M. (2018). Treating traumatic stress in children and adolescents (2nd ed.). The Guilford Press.

Cohen, J. A., Mannarino, A. P., \& Deblinger, E. (2017). Treating trauma and traumatic grief in children and adolescents (2nd ed.). The Guilford Press.

Substance Abuse and Mental Health Services Administration (SAMHSA). (2014). SAMHSA's concept of trauma and guidance for a traumainformed approach. https://ncsacw.samhsa.gov/userfiles/files/SAMHSA_ Trauma.pdf

\section{Expert consultation}

Consultation to enact this policy is required with school mental health professionals, including school psychologists and counsellors, and with external mental health and community wellbeing services. 


\section{References}

American Psychiatric Association [APA]. (2013). Diagnostic and statistical manual of mental disorders, Fifth edition (DSM-5) (5th ed.). American Psychiatric Association.

Berger, E. (2019). Multi-tiered approaches to trauma-informed care in schools: A systematic review. School Mental Health, 11(4), 650-664.

Blaustein, M. E., \& Kinniburgh, K. M. (2018). Treating traumatic stress in children and adolescents (2nd ed.). The Guilford Press.

Centers for Disease Control and Prevention [CDC]. (2019). Preventing adverse childhood experiences: Leveraging the best available evidence. https://1jhpx52ed2172zja 983tp5xl-wpengine.netdna-ssl.com/wp-content/uploads/2019/09/preventin gACES-508.pdf

Cohen, J. A., \& Mannarino, A. P. (2015). Trauma-focused cognitive behavior therapy for traumatized children and families. Child and Adolescent Psychiatric Clinics of North America, 24(3), 557-570.

Copeland, W. E., Keeler, G., Angold, A., \& Costello, E. J. (2007). Traumatic events and posttraumatic stress in childhood. Archives of General Psychiatry, 64(5), 577-584.

Dorado, J. S., Martinez, M., McArthur, L. E., \& Leibovitz, T. (2016). Healthy Environments and Response to Trauma in Schools (HEARTS): A whole-school, multilevel, prevention and intervention program for creating trauma-informed, safe and supportive schools. School Mental Health, 8(1), 163-176.

Holmes, C., Levy, M., Smith, A., Pinne, S., \& Neese, P. (2015). A model for creating a supportive trauma-informed culture for children in preschool settings. Journal of Child and Family Studies, 24(6), 1650-1659.

Jaycox, L. H., Langley, A. K., Stein, B. D., Wong, M., Sharma, P., Scott, M., \& Schonlau, M. (2009). Support for students exposed to trauma: A pilot study. School Mental Health, 1(2), 49-60.

Kezelman, C., Hossack, N., Stavropoulos, P., \& Burley, P. (2015). The cost of unresolved childhood trauma and abuse in adults in Australia. https://www.blueknot.org. au/Portals/2/Economic $\% 20$ Report/The $\% 20 \operatorname{cost} \% 20$ of $\% 20$ unresolved $\% 20$ trauma_ budget $\% 20$ report $\% 20$ fnl.pdf

Perfect, M. M., Turley, M. R., Carlson, J. S., Yohanna, J., \& Saint Gilles, M. P. (2016). School-related outcomes of traumatic event exposure and traumatic stress symptoms in students: A systematic review of research from 1990 to 2015. School Mental Health, 8(1), 7-43.

Substance Abuse and Mental Health Services Administration [SAMHSA]. (2014). SAMHSA's concept of trauma and guidance for a trauma-informed approach. http:// store.samhsa.gov/shin/content//SMA14-4884/SMA14-4884.pdf 